\title{
LA INTECULTURALIDAD EN DIÁLOGO CON LA NEUROFILOSOFÍA PRÁCTICA ${ }^{1}$
}

\author{
INTERCULTURALITY IN DIALOGUE WITH PRACTICAL \\ NEUROPHILOSOPHY
}

\author{
Jesús Conill Sancho ${ }^{2}$ \\ Universidad de Valencia (España)
}

Recibido: 30-11-2014

Aceptado: 02-02-2015

\begin{abstract}
Resumen: El propósito de este artículo es poner en diálogo el discurso sobre la interculturalidad con el nuevo enfoque de las neurociencias en una posible neurofilosofía práctica. Primero se muestra el significado de la perspectiva de la interculturalidad (a diferencia de multiculturalidad) y se consideran algunos caminos para una posible ética intercultural. Y, en segundo lugar, se reflexiona sobre las posibilidades y límites de la neurofilosofía, y se plantea la cuestión de si las neurociencias pueden alumbrar una neurofilosofía práctica que sea capaz de fundamentar las exigencias éticas de la perspectiva de la interculturalidad antes expuesta.
\end{abstract}

Palabras-clave: Interculturalidad, Diálogo, Neuroética, Ética intercultural, Neurofilosofía práctica

\begin{abstract}
The purpose of this article is to address the discourse of interculturality from the new perspective of neurosciences in a (possible) practical neurophilosophy. First, the meaning of the context for interculturality is given (which is different from multiculturalism) and paths for possible intercultural ethics are considered. Second, a reflection is made upon the limits and possibilities of neurophilosophy while contemplating if neurosciences can clarify the idea of a practical neurophilosophy that is able to consolidate ethical demands from the perspective of interculturality previously mentioned.

Key-words: Interculturality, Dialogue, Neuroethics, Intercultural Ethics, Practical Neurophilosophy
\end{abstract}

[1] Este estudio se inserta en los Proyectos de Investigación Científica y Desarrollo Tecnológico FFI2013-47136-C2-1-P, financiado por el Ministerio de Economía y Competitividad y en las actividades del grupo de investigación de excelencia PROMETEO de la Generalidad Valenciana.

[2] (Jesus.Conill@uv.es) Catedrático de Filosofía Moral y Política de la Universidad de Valencia. Entre sus publicaciones destacan: El tiempo en la filosofía de Aristóteles (Valencia, Edilva, 1981); El crepúsculo de la metafísica (Anthropos, Barcelona, 1988), El enigma de animal fantástico (Madrid, Tecnos, 1991); El poder de la mentira (Madrid, Tecnos, 1997); Horizontes de economía ética (Madrid, Tecnos, 2004); Ética hermenéutica (Madrid, Tecnos, 2006). 


\section{Introducción}

Uno de los estudios filosóficos más relevantes que se plantean en el momento actual con respecto a la interculturalidad puede ser el del diálogo con las neurociencias como uno de los frentes más relevantes de la investigación de las últimas décadas. $\mathrm{Y}$, en ese contexto, tiene pleno sentido que concretemos ese diálogo en el seno del diálogo de la interculturalidad con las nuevas posibilidades de estudiar el cerebro mediante los avances en las neurociencias y su repercusión para la filosofía en general y para la filosofía práctica en particular ${ }^{3}$.

En realidad, se trata de un renovado diálogo entre ciencia y filosofía, pero ahora no sólo con las ciencias humanas y sociales, sino con las naturales, que vuelven a creerse en muchas ocasiones como ciencias "puras". Antes se decía -y se creía- que la filosofía era el saber puro (se hablaba de "filosofía pura"), ahora creen serlo algunas ciencias. Pero, ni la ciencia ni la filosofía son puras, como la autocomprensión hermenéutica de tales actividades intelectuales ha puesto de manifiesto por diversos caminos.

Lo mejor es empezar el potencial diálogo entre la interculturalidad y la neurofilosofía práctica presentando a los interlocutores del diálogo, para establecer los términos del mismo y ver qué reflexiones nos puede aportar para entendernos mejor a nosotros mismos, para proseguir el interminable camino del autoconocimiento, el viejo y siempre nuevo apotegma "conócete a ti mismo".

\section{El ámbito de la cultura}

La cultura es el conjunto de procesos que desarrollan las potencialidades transformadoras del medio en que se viven los seres humanos ${ }^{4}$. El estudio de la cultura humana se ha llevado a cabo desde la perspectiva del universalismo ilustrado, planteando el progreso y la mejora del hombre, pero ha tenido el inconveniente de considerar lo humano, el carácter de la humanidad, de un modo demasiado abstracto y uniformizador. De ahí que surgieran otras tendencias que han resaltado la diversidad cultural, los diversos modos de vida, por ejemplo, el Volkgeist, como lo específico de la humanidad. Esta segunda línea reforzó el enfoque que defendía la relatividad de las culturas y que cada cultura posee su propia racionalidad, de manera que las culturas serían inconmensurables y sus contenidos más propios intraducibles.

La línea relativizadora parece olvidar los fenómenos del poder, la dominación, la alienación, la explotación y la manipulación, que se dan en las más diversas culturas. Por tanto, hay que preguntarse si no se pueden comparar realmente los diversos aspectos y pautas culturales, si no se pueden elegir y se-

[3] Cortina, A. (ed.): Guía Comares de Neurofilosofía práctica, Granada, Ed. Comares, 2012.

[4] Ariño, A.: "Cultura", en Conill, J. (coord.), Glosario para una sociedad intercultural, Valencia, Bancaja, pp. 77-88; Sociología de la cultura, Barcelona, Ed. Ariel, 1997.

THÉMATA. Revista de Filosofía, №52 julio-diciembre (2015) pp.: 77-92 doi: 10.12795/themata.2015.i52.04 
leccionar de acuerdo con algunos criterios. De hecho, no sólo desde una perspectiva teórica, sino desde los dinamismos efectivos de la vida, se han producido en la historia continuamente procesos de aculturación e hibridación, que aportan un nuevo enfoque cultural, que para algunos constituye una cierta interculturalidad. La aculturación es un término introducido por J.W. Powell, hacia 1880, para aludir al proceso de transformación de los modos de vida y de pensamiento de los inmigrantes en contacto con la sociedad [norte]americana ${ }^{5}$. Es una forma de cambio cultural que resulta del contacto directo y continuo entre grupos de culturas diferentes, que entrañan cambios en las pautas culturales iniciales de uno o de los dos grupos, produciéndose una reciprocidad de influencias. Lo que nos muestra este tipo de relación intercultural es una vez más que no existen culturas puras, que semejante idea es una trampa ideológica.

Lo que hay que seguir planteándose es el problema de la validez universal de ciertos componentes culturales, en cualquiera de sus posibles expresiones, sea a través de principios, valores, virtudes y/o prácticas. No hay más remedio que seguir pensando y profundizando en la posible relación entre universalismo (lo común) y la diferencia (la apertura); por ejemplo, preguntando si no hay un cierto consenso básico de valores comunes. En definitiva, por una vía $\mathrm{u}$ otra, hay que indagar si no es posible un universalismo no homogeneizador, ni uniformizante, que reconoce lo humano en la diversidad de sus manifestaciones. Uno de los caminos a tal efecto es el de la hermenéutica crítica ${ }^{6}$, que se sitúa entre el procedimentalismo y el sustancialismo, y permite diferenciar (que no separar) entre mínimos (exigibles) y máximos (propuestas y aspiraciones) morales.

\section{La perspectiva de la interculturalidad}

Cuando se habla de interculturalidad hay que precisar en qué sentido se está empleando el término y qué significa realmente ${ }^{7}$. En principio, expresa la realidad de la convivencia de (entre) culturas, que ha sido -y es- una relación problemática y hasta conflictiva. Porque las sociedades han tendido a buscar la homogeneidad y la cohesión, entendiendo la identidad cultural propia por oposición a las demás culturas. Este hecho ha provocado enfrentamientos, incluso llegando a considerarse unos como humanos frente a otros que son considerados menos humanos, infrahumanos, o hasta no humanos. En realidad, se ha tardado bastante en llegar a tener un sentimiento de humanidad compartida y a expresarlo mediante nociones universalistas como "humanidad" o "género

\section{[5] Ibidem.}

[6] Cortina, A.: Ética mínima, Madrid, Ed. Tecnos, 1986; Ética sin moral, Madrid, Ed. Tecnos, 1991; Alianza y contrato, Madrid, Ed. Trotta, 2001; Ética de la razón cordial, Oviedo, Ed. Nobel, 2007; Conill, J.: Ética hermenéutica, Madrid, Ed. Tecnos, 2006.

[7] Conill, J. (coord.): Glosario para una sociedad intercultural, Valencia, Bancaja, 2002.

THÉMATA. Revista de Filosofía, №52 julio-diciembre (2015) pp.: 77-92 doi: 10.12795/themata.2015.i52.04 
humano". Y no ha sido fácil mantener ese espíritu de humanidad común a lo largo de la historia, ni en la teoría ni en la práctica.

El punto de partida en el mundo actual es ya el de que casi todas las naciones son multiculturales, debido a las grandes corrientes migratorias de todos los tiempos. No hay razón alguna para sacralizar las culturas ni para entenderlas como entes separados, sino como producto de procesos de fusión de horizontes ${ }^{8}$. Por tanto, es muy difícil, por no decir imposible y desacertado, defender una incomunicabilidad e inconmensurabilidad de las culturas, como si fueran entes cerrados en sí mismos, y de ahí derivar una serie de consecuencias nefastas para la convivencia efectiva.

Cuando se habla de interculturalidad, en muchas ocasiones se la ha entendido, sin embargo, como multiculturalidad, procedente de ciertas minorías étnicas o culturales, o como resultado de la inmigración. Pero no deberían confundirse los términos con los que nos referimos a situaciones reales diferentes. Habría que distinguir tres posiciones: la integración por asimilación, la multiculturalidad y la interculturalidad.

La integración por asimilación consiste en dejar las señas de identidad cultural y acomodarse plenamente a la cultura dominante, lo cual conlleva o tiende al imperialismo cultural. La multiculturalidad consiste en la configuración de un cierto mosaico cultural, lo cual implica que las minorías formen guetos en los que quedan recluidas sus culturas. La interculturalidad propiamente dicha consiste en un intercambio, un mestizaje, aun perdiendo señas de identidad, que puede acabar en una asimilación de unas culturas por otras, las más poderosas (debido a la técnica, la economía, la lengua, la geoestrategia, etc.), pero al menos siempre como producto de una integración cultural de la pluriculturalidad y del pluralismo.

Estos dinamismos plantean uno de los asuntos más importantes de la convivencia humana, que es el del pluralismo real, que nos conduce a la cuestión de la posibilidad de una ética universal, transcultural o intercultural, un reto para las teorías éticas universalistas tradicionales de la modernidad y, actualmente, para la neurofilosofía práctica. ¿Puede descubrirse o alcanzarse una ética universal de máximos (aspiraciones) o de mínimos (exigencias)? ¿Se puede lograr a través del regreso a la naturaleza humana? ¿Es en ese nivel donde podemos encontrar las bases del progreso moral, de la humanización y del pluralismo cultural? ¿Al propio discurso y a la posición de la interculturalidad (como posición más humanizadora) se llega exclusivamente a través de los descubrimientos de las neurociencias o se necesita recurrir a otros dinamismos humanos?

[8] Gadamer, H.-G.: Verdad y método, Salamanca, Ed. Sígueme, 1977.

THÉMATA. Revista de Filosofía, Nº52 julio-diciembre (2015) pp.: 77-92 doi: 10.12795/themata.2015.i52.04 
Construir una sociedad intercultural no es tarea fácil. Tampoco lo es comprender la interculturalidad y trabajar por ella. Supone una opción creadora en favor de una mejor convivencia, la que puede resultar de la diversidad de culturas. Pero no es fácil vivir en libertad y asumir el hecho (y el proyecto) del pluralismo, que es una de sus expresiones. Sólo el respeto y el reconocimiento mutuo pueden armonizar las diferencias. Pero "armonizar" no significa "homogeneizar", sino hacer compatibles y fecundas las diferencias.

Un componente ineludible de la perspectiva de la interculturalidad es su carácter ético. Un êthos que se expresa en un lógos, porque no hay lógos sin êthos y esa conexión se hace vital en las sociedades interculturales.

Y el medio para avanzar en la construcción de una sociedad intercultural es la integración, a diferencia de la asimilación o la inserción ${ }^{9}$. Según Joaquín García Roca, la asimilación se basa en una metáfora biológica, la de un organismo vivo que absorbe y asimila lo otro diferente haciéndolo semejante; de ahí que implique una uniformización y dominación, dando como resultado una sociedad homogénea, en la que hay que acomodarse quedando absorbido. Por su parte, la inserción se basa en una metáfora física, según la cual unas cosas se colocan junto a otras; de ahí que se entienda como una coexistencia por yuxtaposición de culturas, cuyo resultado es una sociedad multicultural o pluricultural, en la que no hay auténtica interacción y se olvida la dimensión de la subjetividad.

A diferencia de la asimilación y la inserción, la integración cultural consiste en un mestizaje, en auténtica interculturalidad. La metáfora en este caso es la del mundo personal y cuenta con la interacción en la convivencia efectiva y con la subjetividad personal. Los dinamismos de la integración mediante la comunicación y el intercambio fomentan el posible perfeccionamiento mutuo manteniendo las diferencias mediante procesos de aculturación. Los dinamismos culturales contribuyen a capacitar en la propia autonomía de las personas y hacen crecer el sentido del "nosotros" humano ${ }^{10}$.

\section{3. ¿Ética intercultural?}

Es necesaria una ética común, universal, global, planetaria, intercultural. Para eso se requieren procesos que, por supuesto, no consistan en la eliminación del otro, ni tampoco en la segregación, ni en la asimilación, ni siquiera sólo en la inserción, sino en procesos de auténtica integración, lo cual implica un reconocimiento mutuo participando de la vida en común.

[9] GARCÍA ROCA, J.: "Integración", en CONILL, J. (coord.), Glosario para una sociedad intercultural, pp. 203-211.

[10] Ibidem.

THÉMATA. Revista de Filosofía, $\mathrm{N}^{\circ} 52$ julio-diciembre (2015) pp.: 77-92 doi: 10.12795/themata.2015.i52.04 
Cada persona vive su identidad desde el reconocimiento de los otros, entendiendo por identidad "el trasfondo sobre el que adquieren sentido nuestros gustos y deseos, opiniones y aspiraciones"11. Lo básico para la vida social, para la convivencia, es el reconocimiento recíproco, esa es la necesidad primordial de la vida humana ${ }^{12}$. Esa relación se vive dentro de cada cultura como cosmovisión, como modo de vida, de concebir el sentido de la vida y de la muerte, que justifica en forma de tradición (intergeneracionalmente) las normas y lo valores. El problema surge cuando entran en colisión cuestiones de justicia. El pluralismo cultural requiere unos mínimos de justicia entre las distintas concepciones de vida buena.

Pero hay varias concepciones que intentan posibilitar el pluralismo cultural. En primer lugar, es muy destacable la posición rawlsiana de una concepción ético-política de la justicia ${ }^{13}$. Pero, entre nosotros, tenemos la propuesta desde hace años de una "ética mínima"14, que pueda ser compartida por las diversas éticas de máximos y, por tanto, permita convivir, manteniendo la autonomía personal y el diálogo, el respeto y el reconocimiento, nutriéndose de un aprendizaje histórico mutuo.

Desde la perspectiva de una ética intercultural o transcultural (que no hay que confundir con el multiculturalismo), se entiende la convivencia como un proceso de aportaciones recíprocas entre los diversos agentes con diversidad cultural, porque ninguna cultura es autosuficiente, ni pura, sino que siempre estamos en un proceso de configuración cultural de lo humano con posibilidades y opciones cambiantes a través de la interacción. Por consiguiente, hay que rechazar el mito de la inconmensurabilidad cultural y su presunta autoidentidad insuperable, así como el relativismo cultural.

Ha sido posible detectar ciertos "universales culturales", como la familia, el parentesco, los ritos, la llamada "Regla de Oro", que son aplicables y vividos de forma diferente. A lo que cabe añadir la efectiva permeabilidad de las culturas, su apertura interna y el innegable hecho de las mutuas influencias, porque vivimos siempre en real o virtual fusión de horizontes experienciales y vitales.

Otro de los posibles contenidos básicos de una ética intercultural son los denominados "derechos humanos" ${ }^{15}$. Se trata de una excelente herencia de

[11] Taylor, Ch.: "La política del reconocimiento", en Gutmann, A. (ed.): El multiculturalismo y la política del reconocimiento, p. 54.

[12] Hegel, G.W.F.: Fenomenología del espíritu, México, F.C.E., 1971; Fukuyama, F.: El fin de la historia y el último hombre, Barcelona, Ed. Planeta, 1992.

[13] Rawls, J.: El liberalismo político, Barcelona, Crítica, 1996.

[14] Cortina, A.: Ética mínima, Madrid, Ed. Tecnos, 1986; Ética sin moral, Madrid, Ed. Tecnos, 1991; Alianza y contrato, Madrid, Ed. Trotta, 2001; Ética de la razón cordial, Oviedo, Ed. Nobel, 2007.

[15] Rubio Carracedo, J.: "Ética intercultural" en Conill, J. (coord.): Glosario para una sociedad intercultural, pp. 149-160; Carrillo, J.A.: Dignidad frente a barbarie, Madrid, Ed. Trotta, 1999.

THÉMATA. Revista de Filosofía, $\mathrm{N}^{\circ} 52$ julio-diciembre (2015) pp.: 77-92 doi: 10.12795/themata.2015.i52.04 
Occidente, que se encuentra todavía en un proceso inacabado. Como su propio origen y sus raíces son ya interculturales, aunque su desarrollo se haya producido preferentemente en Occidente, según Rubio Carracedo, constituye una plataforma aprovechable para el diálogo intercultural.

Pero no existe un reconocimiento universal de los derechos humanos, ni se cumplen con facilidad. Antes bien, hay quienes los consideran una creencia ilusoria ("como creer en brujas y unicornios") ${ }^{16} \mathrm{y}$, a lo sumo, se renuevan las declaraciones (Viena, 1993), pero de modo diferenciado, adaptando histórica y culturalmente su universalización, como en las Conferencias Africana (1992) y Asiática (1993).

Lo decisivo en esta cuestión de los derechos humanos es la exigencia de promover y proteger un núcleo fundamental, que garantice con precisión el valor de la dignidad de toda persona humana y las correspondientes exigencias primordiales (su vida, libertad, seguridad, no discriminación y servicios mínimos). Éste sería el límite del pluralismo, que algunos han llamado "razonable", en un horizonte intercultural.

Las estrategias para defender alguna forma de universalización diferenciada, expuestas por Rubio Carracedo ${ }^{17}$, son las de la cultura política (Rawls), la racionalidad comunicativa (Habermas), la búsqueda de denominador común (Walzer) y el pragmatismo contextualista (Rorty). Cada una tiene sus ventajas y sus inconvenientes. Pero en todas ellas se presupone, de un modo diferente (explícita o incluso implícitamente), alguna forma de universalización, capaz de hacer frente a la interculturalidad, sobre la base del nivel "postconvencional" de la conciencia moral ${ }^{18}$. No obstante, hay que seguir repensando acerca de las virtualidades de cada una de las líneas propuestas: ¿Un consenso solapante mundial? ¿La fuerza del mejor argumento en el proceso de deliberación? ¿Un común denominador en las prácticas reales? ¿Valores interculturales y/o transculturales efectivos (funcionando)?

Para el tema que nos ocupa hay que preguntarse cómo se determinan los contenidos de la mejor cultura política mediante consenso solapante, o bien qué significa el mejor argumento y si realmente por ser tal tendría fuerza suficiente para imponerse, si es fiable el procedimiento de búsqueda del común denominador, y cómo se seleccionan los valores y los sentimientos, etc., que están siendo efectivos en los procesos históricos y contextualizados pragmáticamente. ¿Qué aporta el enfoque neurocientífico, en el diálogo interdisciplinar, para la resolución de todos estos asuntos?

[16] MacIntyre, A.: Tras la virtud, Barcelona, Crítica, 1987, p. 95.

[17] Rubio Carracedo, J.: "Ética intercultural", pp. 155-160.

[18] Kohlberg, L.: Psicología del desarrollo moral, Bilbao, Desclée de Brouwer, 1992; Apel, K.-O., Diskurs und Verantwortung, Frankfurt a.M., Suhrkamp, 1988; Habermas, J.: Conciencia moral y acción comunicativa, Barcelona, Península, 1985.

THÉMATA. Revista de Filosofía, $\mathrm{N}^{\circ} 52$ julio-diciembre (2015) pp.: 77-92 doi: 10.12795/themata.2015.i52.04 


\section{La interculturalidad en tiempo de neurociencia.}

\section{1. ¿Neurofilosofia?}

Estamos en tiempos de una presunta filosofía neurocientífica, pues, como ha señalado Diego Gracia, los neurofisiólogos son con frecuencia "algo así como científicos transmutados en filósofos". Pero la filosofía exige tener una formación y utilizar unos métodos adecuados. En filosofía no todo vale. Por eso hay que aprovechar los nuevos conocimientos científicos, pero con auténtico sentido filosófico, bien elaborado y fundado ${ }^{19}$. Por ejemplo, la filosofía naturalizada mediante la neurociencia y las presuntas evidencias empíricas de los hallazgos neurobiológicos no son base suficiente para ciertas distinciones conceptuales, como el de tener o no control de las propias acciones (un cierto equivalente funcional de la libertad), y, desde luego, no son fundamento de nociones normativas ${ }^{20}$. Asimismo, con mucha razón, Bennett y Hacker critican el reduccionismo neurocientífico, porque comete una "falacia mereológica" 21 , al atribuir propiedades a las partes que deberían atribuirse al todo.

La neurofilosofía dependerá del tipo de filosofía, es decir, del método filosófico correspondiente, y asimismo de la concepción que se tenga de la relación entre filosofía y ciencia. Si el método de la filosofía queda sustituido por el de las ciencias y el único conocimiento es el que proviene de las ciencias, y en el caso de la neurofilosofía el que proviene de las neurociencias, entonces la filosofía queda vaciada de sus métodos tradicionales; pero, entonces, éstos han de ser superados por el nuevo tipo de investigación, de tal manera que sus conceptos fundamentales tendrían que ser explicados por los conocimientos neurocientíficos. En cambio, si la relación entre filosofía y ciencia no es de sustitución de la primera por la segunda, sino que se mantiene el estatuto de ambas en su especificidad, entonces habrá que ver cómo se complementan las aportaciones de cada una de ellas (como ocurre, por ejemplo, en la Noología de Zubiri) ${ }^{22}$.

Aunque resulte chocante, una característica de una buena parte de los proyectos de neurofilosofía es la de adentrarse por los terrenos de la metafísica. Con gran facilidad los neurocientíficos caen en la tentación de la metafísica. Empezando por el atractivo del determinismo, pasando por el uso de los

[19] Gracia, D.: Conferencia sobre "Neuroética", Facultad de Filosofía y Ciencias de la Educación, Universidad de Valencia (2-XI-2009). Vid. Recerca, 13 (2013): "Retos actuales de la neuroética".

[20] Buller,T.: "Brains, lies, and psychological explanations" en Illes, J. (ed.): Neuroethics, Oxford, University Press, 2008, p. 51-60; Churchland, P. S.: "Moral decision-making and the brain" en Illes, J. (ed.): Neuroethics, p. 3-16.

[21] Bennett, M.R. y Hacker, P.M.S.: Philosophical Foundations of Neuroscience, Oxford, Blackwell, 2003.

[22] Zubiri, X.: Inteligencia sentiente, Madrid, Alianza, 1980.

THÉMATA. Revista de Filosofía, Nº52 julio-diciembre (2015) pp.: 77-92

doi: 10.12795/themata.2015.i52.04 
conceptos más tradicionales de la metafísica, como el de esencia, ofrecen sus servicios incluso para explicar presuntamente nociones como la de "dignidad humana" (que está bastante alejada de cualquier evidencia empírica).

Una lección que puede aprenderse de la genética es la de evitar convertir la neurociencia en una metafísica neuronómica. Hubo una tendencia a convertir la genética en la base de una metafísica que iba más allá del conocimiento que la ciencia misma ofrecía ${ }^{23}$. Era fácil deslizarse hacia una teoría de la naturaleza humana, diciendo que "somos nuestros genes" y que casi se convirtió en un eslogan. Habría que ir con cuidado para no incurrir de nuevo en extrapolaciones, al intentar explicarlo todo desde la nueva perspectiva neuronal.

Pues igual que hubo una tendencia a "metafisicalizar" el genoma, es decir, convertir los genes en entes metafísicos, hasta convertirse en una especie de metafísica genética o metafísica genómica, que llegó a equiparar el genoma y el alma, algo parecido o todavía peor puede suceder con la neurociencia, dado que ésta aún es más susceptible que la genética a la seducción metafísica. Porque el cerebro está más cerca del núcleo del yo (self) que los genes. Comprender el cerebro de una persona implica una profunda penetración del yo. Tendríamos así una ciencia del cerebro convertida en metafísica, que definiría el rasgo biológico que identificaría nuestra humanidad, que ahora ya no serían los genes, sino la actividad neural. De este modo se habría convertido la ciencia en metafísica y estaríamos ante una "neurociencia metafísica" ${ }^{24}$ o bien una metafísica neurómica.

De hecho, Adina Roskies ha señalado que muchos creen en una especie de "neuroesencialismo" (parecido al esencialismo genético), en que nuestros cerebros definen quiénes somos, incluso más que nuestros genes, que era lo que se defendía en el tiempo de la predominancia del esencialismo genómico. Pues investigando el cerebro, parece que estemos investigando más directamente el self. El genoma humano es, al menos en parte, "lo que nos hace". Pero el cerebronoma (brainome) todavía toca más quién "somos" fundamentalmente ${ }^{25}$.

Por consiguiente, el esencialismo genómico (o genético) va siendo sustituido por el esencialismo neuronal. Y lo mismo ocurre con el determinismo: el genético va dejando paso al neuronal. Esta última posición esencialista se refuerza por el hecho de que tenemos una tendencia a creer que somos nues-

[23] Fernández, J.: Fundamentos biológicos de la moral, Valencia: Universidad de Valencia, 2010. Tesis de doctorado.

[24] Green, R. M.: "From genome to brainome: charting the lessons learned" en Illes, J. (ed.): Neuroethics, cit., p. 105-121.

[25] Roskies, A.: "Neuroethics for the New Millennium" en Glannon, W. (ed.): Defining Right and Wrong in Brain Science, New York, Dana Press, 2007, p. 12-18; Illes, J. y Racine, E.: "Imaging or Imagining?" en Glannon, W. (ed.): Defining Right and Wrong in Brain Science, cit. p. 140-162.

THÉMATA. Revista de Filosofía, №52 julio-diciembre (2015) pp.: 77-92 doi: 10.12795/themata.2015.i52.04 
tros cerebros. Sin embargo, estudios de la plasticidad del cerebro y de su reorganización tras alguna lesión han demostrado que tal visión reduccionista es incompleta si no se tiene en cuenta la intervención de factores externos y culturales $^{26}$. Además, algunos han argüido con razón que las ciencias biológicas, que tratan de sistemas abiertos, no se ajustan a leyes universales y deterministas como las físicas y químicas ${ }^{27}$.

Un rasgo novedoso de la actual neurofilosofía es la innovación tecnológica que emplea para recabar la información más relevante. A partir de la visualización cerebral mediante la neuroimagen (neuroimaging), se ha reforzado la idea de que "somos sistemas físicos", ya que "los cerebros son sistemas físicos" y los cambios en el cerebro dan como resultado cambios en la persona. No obstante, nuestras intuiciones acerca de la persona no encajan fácilmente en esta comprensión tan reducida de la misma, a pesar de las nuevas tecnologías para visualizar el cerebro ${ }^{28}$.

La neurofilosofía se ha querido convertir en una nueva "ciencia unificada" con valor metafísico, capaz de unificar todos los posibles conocimientos sobre el hombre y de "conocer quiénes somos, en nuestra genuina realidad". Ahora lo importante es conocer la gran transformación del cerebro en el proceso evolutivo para saber "cómo opera", ya que se trata del "órgano productor de cuanto somos y origen último de cómo nos comportamos" ${ }^{29}$. La neurociencia, aun siendo "una ciencia experimental" que utiliza el método científico para "explicar cómo funciona el cerebro", aportaría el auténtico conocimiento de "la esencia del mismo ser humano" y, por tanto, posibilitaría la comprensión de nosotros mismos ${ }^{30}$.

Desde esta perspectiva neurofilosófica, los neurobiólogos se plantean las mismas preguntas que los filósofos clásicos, pero al parecer intentan responder, no recurriendo a los conceptos tradicionales, sino a los nuevos conocimientos neurofisiológicos del cerebro y, en concreto, a los mecanismos cerebrales correspondientes. El cerebro humano es un producto de la selección natural y el mundo "real" en el que vivimos es una consecuencia del constructo del cerebro a partir de los estímulos que recibe del "mundo externo". Por tanto, todo cuanto percibe o concibe el ser humano lo hace a través del trabajo de su propio cerebro. También, pues, cualquier noción de realidad y cualquier experiencia de la realidad como tal. El cerebro constituiría así el sustrato último de

[26] Illes, J. y Racine, E.: “Imaging or Imagining?"en GLANNON, W. (ed.): Defining Right and Wrong in Brain Science, cit., nota 53, p. 160.

[27] Ibidem, nota 54, p. 160.

[28] Farah, M.J. y Wolpe, P. R.: "Monitoring and Manipulating Brain Function: New Neuroscience Technologies and Their Ethical Implications" en Glannon, W. (ed.): Defining Right and Wrong in Brain Science, cit., p. 37-57.

[29] Mora, F.: Neurocultura, cit., p. 44 y 24.

[30] Ibidem, p. 35 у 36.

THÉMATA. Revista de Filosofía, $\mathrm{N}^{\circ} 52$ julio-diciembre (2015) pp.: 77-92 doi: 10.12795/themata.2015.i52.04 
toda experiencia. Y por eso algunos confían en que la neurociencia convertida en neurofilosofía podrá desentrañar el "significado último" de los circuitos neuronales que intervienen en todas las experiencias, incluso las metafísicas, las religiosas y las místicas ${ }^{31}$.

Llama poderosamente la atención que este enfoque neurofilosófico a partir de las neurociencias defienda un tajante realismo, presuntamente científico (¿no habría que decir cientificista?): "aun siendo filtrada la realidad por nuestra biología, es "realidad" y nuestra única "realidad real". En esto no hay desafío posible a la ciencia". No habría otra realidad para el ser humano que la que vemos y alcanzamos conocer a través del método científico, y esto sería así, "porque tenemos el cerebro que tenemos" 32 . Por tanto, desde esta nueva perspectiva neurofilosófica, quien quiera "filosofar con rigor" habrá de atenerse a los nuevos conocimientos científicos: "De la convergencia, pues, entre ciencia y filosofía debe devenir un entendimiento filosófico más profundo de quiénes somos y encontrar con ello un nuevo sentido, si es que éste existe, a nuestra propia existencia”. Ésta parece ser la tarea que se propone la neurofilosofía.

Estas concepciones de la neurofilosofía prosiguen y fomentan la línea que propuso Patricia S. Churchland: "La neurociencia va conformando nuestra concepción de lo que somos". "Es el cerebro (...) lo que siente, piensa y decide". "Ahora entendemos que esos importantes sentimientos [amor, etc.] son sucesos que ocurren en el cerebro físico" ${ }^{33}$. Con lo cual la mente se reduciría a la actividad del cerebro mismo. La mente como tal no existiría, lo único de lo que habría constancia en relación a los procesos mentales serían los correspondientes procesos de actividad neuronal.

De todos modos, a pesar de la gran influencia que han ido adquiriendo las posiciones antes aludidas de la neurofilosofía, lo que no se puede negar que ocurre en la conciencia social contemporánea es que existen dos lenguajes: el neurobiológico y el psicológico (el propio del lenguaje ordinario), cuya raíz se encuentra siempre en el mundo de la vida ${ }^{34}$. Y, por tanto, habría dos interpretaciones de tales procesos, pues a la descripción en términos neurobiológicos se añade una interpretación psicológica y humanística, más cercana a la concepción cotidiana de la vida humana. De aquí surge una enorme cantidad de problemas filosóficos que no se pueden obviar. Además de los importantes problemas del reduccionismo neurológico, la causalidad cerebro-mente y la entidad de lo mental, hay bastantes

[31] Ibidem, p. 58, 62-63. Vid. también Bonete, E.: "Neuro-religión" en Cortina, A. (ed.): Guía Comares de Neurofilosofía práctica, p. 97-124.

[32] Ibidem, p. 51.

[33] Churchland, P. S.: Brain-Wise, Cambridge, MIT Press, 2002. Vid., no obstante, Damasio, A.: El error de Descartes, Barcelona, Crítica, 2006 y Morgado, I.: Emociones e inteligencia social, $2^{a}$ edición. Barcelona, Ariel, 2010.

[34] Habermas, J.: Entre naturalismo y religión, Barcelona, Paidós, 2006; "Die Herausforderung des Naturalismus" en Philosophische Texte. Bd. 5, Frankfurt, Suhrkamp, 2009.

THÉMATA. Revista de Filosofía, №52 julio-diciembre (2015) pp.: 77-92

doi: 10.12795/themata.2015.i52.04 
más, que un enfoque neurofilosófico en serio no puede dejar de plantearse, como son los que surgen en el ámbito de la filosofía práctica y, en concreto, el que aquí se plantea a una posible neurofilosofía práctica: el de la interculturalidad.

\subsection{Neurofilosofía práctica e interculturalidad}

La neurofilosofía práctica se sitúa dentro de un contexto histórico en el que se ha producido un regreso generalizado de la filosofía a la naturaleza humana, tras una época en que esta perspectiva había sido relegada por parte de las corrientes preponderantes de la época, más centradas en el estudio del lenguaje (o incluso exclusivamente dedicadas a tal menester). Ahora asistimos a un proceso de nueva naturalización del pensamiento filosófico, a partir de la revitalización del darwinismo y que se ha expresado a través de los avances de la genética y más recientemente de la neurociencia. Ésta se ha convertido incluso ya en una moda (de ahí que hayan surgido términos como "darwinitis", "neuromanía", "neurotodo", "neuroX", etc.). Por eso lo importante es reflexionar sobre la posible contribución de este enfoque en el ámbito de la filosofía práctica $^{35}$, que ya desde los clásicos engloba la ética, la política, la economía, la jurisprudencia, la retórica e incluso la poética; es decir, el amplio campo de las ciencias humanas (sociales, morales y políticas, económicas, históricas, humanidades).

Lo que hemos de plantearnos ahora es si en el ámbito de esta filosofía práctica desde la perspectiva neurológica cabría hablar de una especie de "neurointerculturalidad". Ciertamente se ha llegado a hablar de "neurocultura", pero de lo que ahora se trata es de dar un paso más allá y ver si los actuales estudios de las neurociencias pueden sustentar una ética universalista, transcultural y postconvencional, que sirvan de base suficiente para los planteamientos expuestos acerca de la interculturalidad. A tal efecto habrá que ver cómo funciona el cerebro y si el estudio de las bases cerebrales permite sustituir las teorías filosóficas sobre la interculturalidad. ¿Tiene el cerebro un carácter social de tal tipo que encaja con las exigencias de la perspectiva de la interculturalidad que hemos expuesto? ${ }^{36}$

Como es bien sabido, el recurso a la naturaleza humana en la filosofía no es nuevo. Desde Grecia, el recurso a la phýsis, en general y de modo sistematizado en Aristóteles, constituye un ingrediente ineludible del pensamiento de la realidad humana, que perdura a través de diversas tendencias modernas que incorporan las novedades de las nuevas ciencias (Psicología, Antropobiología, Sociología, Economía, Genética, Neurología, Computación, etc.). Actual-

[35] Cortina, A. (ed.): Guía Comares de Neurofilosofía práctica, Granada, Comares, 2012; E. Bonete, Neuroética práctica, Bilbao, Desclée, 2010.

[36] Salles, A. y Evers, K. (coords.): La vida social del cerebro, México, Fontamara, 2014.

THÉMATA. Revista de Filosofía, Nº52 julio-diciembre (2015) pp.: 77-92

doi: 10.12795/themata.2015.i52.04 
mente ha crecido la convicción de que la perspectiva "neuro" conforma un saber neurocientífico que es transversal a todos los demás y que estudiar las bases cerebrales de nuestra forma de saber y obrar es dar con el núcleo del quehacer humano en todas sus dimensiones. ¿Se repetiría así, en una nueva versión neurocientífica, la pretensión de una "ciencia unificada", por la que se reduciría el estudio de la mente al del cerebro?

El intento de explicar cómo funciona el cerebro nos remite en España, al menos, de modo especial a Santiago Ramón y Cajal $^{37}$ y a Luis Simarro ${ }^{38}$. Pero en los últimos decenios han proliferado nuevos datos obtenidos a partir de la aplicación de las nuevas técnicas de neuroimagen, que localizan determinadas actividades cerebrales, los vínculos entre distintas zonas y a partir de las posibles correlaciones dicen poder ofrecer una cierta imagen del "cerebro en acción".

Pero las técnicas de neuroimagen no proporcionan fotografías del cerebro, ni el descubrimiento de correlatos entre determinadas actividades de los sujetos y ciertas áreas cerebrales permite establecer una relación causa-efecto. Además hay que advertir de las dificultades de interpretar los datos obtenidos por las técnicas de neuroimagen.

Por supuesto, las aplicaciones de los avances neurocientíficos pueden llegar a ser beneficiosos en la prevención de enfermedades y en la mejora de las capacidades. Y el conocimiento de la plasticidad del cerebro (la capacidad de adaptación y de aprendizaje) puede tener importantes consecuencias en el ámbito educativo, que podría reformarse teniendo en cuenta las peculiaridades del cerebro humano.

En la medida en que la neurofilosofía práctica engloba las perspectivas de la ética, la política, la economía, el derecho, la estética, la religión, la educación y la cultura, el diálogo entre la posible neurofilosofía práctica y la interculturalidad ha de plantear si los valores y normas están incrustados en el cerebro o si surgen de la cultura; si los juicios morales y las decisiones, los deberes, la acción presuntamente libre, las instituciones políticas, económicas y educativas pueden explicarse exclusiva o principalmente desde los mecanismos cerebrales.

En definitiva, hay que conocer las posibles aportaciones de las neurociencias a las preguntas de la filosofía práctica: qué podemos y qué debemos hacer, qué nos cabe esperar (de nosotros mismos y de los demás). De hecho, ha sido muy significativo el giro de algunos neurofilósofos muy relevantes, como es el caso de Patricia S. Churchland, quien empezó su propuesta con un libro de "neurofilosofía" de carácter epistemológico, pero que ha pasado a dedicarse

[37] Ramón y Cajal, S.: Recuerdos de mi vida: Historia de mi labor científica, Madrid, Alianza, 1981; Laín Entralgo, P.: Escritos sobre Cajal, Madrid, Triacastela, 2008.

[38] Carpintero, H.: Luis Simarro, Valencia, Universidad de Valencia, 2014.

THÉMATA. Revista de Filosofía, ${ }^{\circ} 52$ julio-diciembre (2015) pp.: 77-92 doi: 10.12795/themata.2015.i52.04 
en los últimos años a la vertiente práctica ${ }^{39}$. Pues con la neurociencia muchos creen poder descubrir las claves para entender la naturaleza humana y, por tanto, qué es lo que somos y nos hace humanos, lo que tanto ha buscado la filosofía, al parecer, inútilmente hasta ahora.

¿Aportan, pues, las neurociencias a una nueva neurofilosofía práctica, en su versión neuroética, un universalismo ético para la interculturalidad? El estudio de ciertos instintos y de algunas intuiciones, que se consideran "morales", ha hecho pensar que la neurociencia es capaz de ofrecernos un nivel prerracional (emocional), a partir del cual se explicarían no sólo los comportamientos más básicos del hombre (como la supervivencia), sino también el juicio moral y el consiguiente comportamiento. El contenido principal de tales instintos e intuiciones con base cerebral consistiría en la tendencia a favorecer al cercano y rechazar al extraño $0^{40}$, como han puesto de manifiesto las diversas versiones de los experimentos que recurren a los ya famosos dilemas ${ }^{41}$.

Por consiguiente, una de las actitudes de algunos neurocientíficos ha sido la de intentar sustituir las éticas filosóficas, en la medida que las consideran parte de una paleofilosofia, que ha de ser sustituida por una nueva filosofía de la vida sustentada por las nuevas ciencias del cerebro. Sin embargo, otros intentan aportar conocimientos sobre una estructura cerebral básica (pero no sobre contenidos morales), que se modularía según las diversas culturas. Se trata de aportaciones que bien podrían servir para actualizar algunas propuestas que desde hace bastante tiempo han caracterizado a una buena parte de la filosofía española contemporánea, como la desarrollada por Xavier Zubiri, José Luis Aranguren, Ignacio Ellacuría, Pedro Laín Entralgo y Diego Gracia ${ }^{42}$.

No obstante, son graves las dificultades de las interpretaciones adaptacionistas del cerebro humano, tal como suelen exponerse en los estudios neurocientíficos, porque lo que se pone de manifiesto es una disonancia (que no suele exponerse ni ser reconocida) con respecto al nivel postconvencional de la conciencia moral, un nivel que es el más propio de las éticas contemporáneas. Por tanto, no habría una ética universalista fundamentada en el cerebro capaz de hacer frente a los retos de la interculturalidad. Indudablemente, las neurociencias sirven para conocernos mejor a nosotros mismos, especialmente para

[39] Churchland, P.S.: Neurophilosophy: Toward a unified science of the mind-brain, Cambridge, MIT, 1986; Braintrust, Princeton, University Press, 2011.

[40] Cortina, A.: Neuroética y neuropolítica, Madrid, Tecnos, 2011.

[41] Haidt, J.: "El perro emocional y su cola racional: un enfoque intuicionista social del juicio moral", en Cortina, A. (ed.): Guía Comares de Neurofilosofía práctica, pp. 159-215.

[42] Zubiri, X.: Sobre el hombre, Madrid, Alianza, 1986; Aranguren, J.L.: Ética, Obras Completas, II, Madrid, Trotta, 1994; ELLACURÍA, I.: "Introdución crítica a la Antropología filosófica de Zubiri", en Realitas II, 1976, Madrid, Sociedad de Estudios y Publicaciones, pp. 49-137; Laín Entralgo, P.: El cuerpo humano, Madrid, Espasa-Calpe, 1989; Gracia, D.: Fundamentos de bioética, Madrid, Triacastela, 2007 ( $2^{\mathrm{a}}$ ed.).

THÉMATA. Revista de Filosofía, $\mathrm{N}^{\circ} 52$ julio-diciembre (2015) pp.: 77-92 doi: 10.12795/themata.2015.i52.04 
explicar la tendencia que nos mueve a favorecer al cercano y rechazar a los extraños, en la medida en que los sentimos como un peligro.

Por tanto, hay que aprovechar los conocimientos que nos aportan las neurociencias todo lo que sea posible para los nuevos debates sobre la naturaleza humana: sobre el impulso básico a sobrevivir y adaptarse, la tendencia preferente a reciprocar y cooperar ${ }^{43}$. Pero la cuestión decisiva es si desde las neurociencias se puede fundamentar algún tipo de progreso moral en los mecanismos evolutivos, que sirva para afrontar la interculturalidad. Por ejemplo, los estudios de la racionalidad económica en perspectiva neurológica, que han configurado también lo que ya se denomina "neuroeconomía" ${ }^{44}$, pueden ayudar a descubrir algunos procesos neurobiológicos que subyacen a la toma de decisiones. En ellos lo primordial son ciertos impulsos (por ejemplo, en función de la recompensa y el castigo) y emociones (avidez, sorpresa, miedo, pánico, etc.), que dan como resultado decisiones instintivas y conforman los instintos sociales más básicos, que podrían tener un alcance transcultural ${ }^{45}$. ¿Existe una neurorracionalidad práctica, cuyos valores biológicos subyacentes hagan juego con la perspectiva de la interculturalidad?

Lo importante sería descubrir si en los aspectos neurológicos se encuentran las claves para entender en qué consiste la racionalidad y, en el tema que nos ocupa, si es la interculturalidad más neurorracional? ¿Se llega a la posición de la interculturalidad a través de las neurociencias que inspiran las diversas vertientes de la neurofilosofía práctica? Una de las aportaciones más importantes de lo que significa la neurorracionalidad consiste en que no es axiológicamente neutral, es decir, no está exenta de valores, como se ha pretendido que sea la racionalidad científica y tecnológica, hasta convertirla en ideología ${ }^{46}$. Por otra parte, la transformación de la filosofía a lo largo de los dos últimos siglos ha mostrado la necesidad de pasar de la estructura de una presunta "razón pura" a una "razón impura", que se alimenta de impulsos, instintos, valores, afectos, sentimientos e intereses, y se traduce en interpretaciones vitales ${ }^{47}$. En el trasfondo de ese inframundo o subsuelo de la razón las neurociencias dicen

[43] Cortina, A.: Neuroética y neuropolítica, cap. 4.

[44] Glimcher, P. W. Glimcher, Camerer, C. F. Camerer, Fehr, E. y Poldrack, R. A. (eds.): Neuroeconomics: Decision Making and the Brain, Londres, Elsevier, 2009; Conill, J.: "Neuroeconomía y neuromarketing" en Cortina, A. (ed.): Guía Comares de Neurofilosofía práctica, pp. 39-64.

[45] Gigerenzer, G.: Decisiones instintivas, Barcelona, Ariel, 2008.

[46] Scheler, M.: Sociología del saber, Buenos Aires, Ed. Siglo Veinte, 1973; Habermas, J.: Ciencia y técnica como "ideología", Madrid, Ed. Tecnos, 1984; APEL, K.O.: La transformación de la filosofía, Madrid, Taurus, 1985.

[47] Gerber, G.: Die Sprache als Kunst, Gaertners Verlagsbuchhandlung, Berlin, 1885 (2. Auflage); Nietzsche, F.: Über Wahrheit und Lüge im aussermoralischen Sinne, Ksa, G. Colli y M. Montinari (Hrsg.), Berlín, de Gruyter, 1999, Bd. 1, pp. 873-890; Conill, J.: El poder de la mentira. Nietzsche y la política de la transvaloración, Madrid, Tecnos, 1997.

THÉMATA. Revista de Filosofía, $\mathrm{N}^{\circ} 52$ julio-diciembre (2015) pp.: 77-92 doi: 10.12795/themata.2015.i52.04 
haber descubierto unos valores biológicos básicos, que subyacen a su expresión a través de las emociones y sentimientos, como ha puesto de relieve Damasio con su hipótesis del "marcador somático" 48 (una noción que ya fue anticipada por Nietzsche, según J.-P. Changeux $)^{49}$.

En el nivel más básico de los procesos de la regulación vital Damasio descubre lo que denomina el "valor biológico". Una idea que "es omnipresente en el pensamiento contemporáneo del cerebro y la mente" ${ }^{50}$. Pero se trata de los valores asociados a la regulación básica de la vida, que primero se lleva a cabo de forma automática e inconsciente, hasta que empieza a regularse por la mente consciente y contando con los sentimientos. Con la emergencia de la mente consciente surgen nuevos dispositivos de regulación, los propios de una "homeostasis sociocultural" 51 , en la que intervienen de modo muy significativo la recompensa y el castigo, y que tiene como objetivo la supervivencia y el bienestar.

La regulación sociocultural amplía las posibilidades de gestionar la vida mediante incentivos y orientaciones eficaces, pero, detrás de las civilizaciones y culturas, la cuestión básica es la "regulación de la vida". Nuestra vida está definida por las decisiones que tomamos, que están "basadas en el valor". La cuestión del valor se convierte en fundamental para la racionalidad cultural. Todo se capta con alguna "indicación de valor" biológico y cultural, en relación con las necesidades vitales (lucha por la supervivencia y búsqueda de bienestar). Para vivir hemos de asignar valor biológico y cultural, teniendo en cuenta las ganancias y las pérdidas, las recompensas y los castigos, y de este dinamismo valorativo emergen las emociones y los sentimientos. ¿Son estas bases neurales de la razón suficiente para responder a las exigencias expresadas desde la nueva perspectiva de la interculturalidad? ¿Basta la neurobiología para orientar la interacción de la interculturalidad, o hace falta la experiencia histórica de carácter sociocultural? ¿No constituye la perspectiva de la interculturalidad un progreso moral y social, que necesita, tanto para su surgimiento como para su mantenimiento y mejora, un contexto de racionalidad sentiente y cordial que cuide de las exigencias éticas que lleva impresas?

[48] Damasio, A.: El error de Descartes, Barcelona, Crítica, 2006; Y el cerebro creó al hombre, Destino, Barcelona, 2010.

[49] Changeux, J.-P.: Sobre lo verdadero, lo bello y el bien, Buenos Aires, Katz, 2010, p. 49.

[50] Damasio, A.: Yel cerebro creó al hombre, Destino, Barcelona, 2010, p. 83.

[51] Ibidem, p. 54.

THÉMATA. Revista de Filosofía, №52 julio-diciembre (2015) pp.: 77-92 doi: 10.12795/themata.2015.i52.04 